\title{
A comunicação institucional e o conteúdo gerado pelos usuários no Facebook envolvendo a companhia TIM
}

\author{
The institutional communication and the users' generated content on \\ Facebook involving mobile phone company TIM
}

\footnotetext{
Suelen Loraine Aguilar Albuquerque ${ }^{[a]}$, Cibele Abdo Rodella ${ }^{[b]}$

[a] Jornalista, especialista em Gestão da Comunicação Organizacional e Negócios pelo Centro Universitário de Maringá (Cesumar), Maringá, PR-Brasil, e-mail: sueloraine_1212@hotmail.com

[b] Jornalista, mestre em Comunicação pela Universidade Estadual de Londrina (UEL), coordenadora da pós-graduação em Gestão da Comunicação Organizacional e Negócios do Centro Universitário de Maringá (Cesumar), professora do curso de Comunicação e Multimeios da Universidade Estadual de Maringá (UEM), Maringá, PR-Brasil, e-mail: cibeleabdo@gmail.com
}

\begin{abstract}
Resumo
A pesquisa propôs compreender de que forma os consumidores e usuários do Facebook geram conteúdo que produz sentidos na comunicação institucional da organização TIM (Telecom Italia Mobile). A partir das proposições da comunicação organizacional e dos procedimentos metodológicos da Análise de Conteúdo, da pesquisadora francesa Laurence Bardin, a investigação foi desenvolvida. O objeto de estudo do trabalho é a comunicação presente no Facebook, produzida por meio das informações e opiniões compartilhadas, comentadas e curtidas por usuários. Com o processo analítico, observou-se que quando as exposições de conteúdo negativo na rede mundial repercutem e se tornam notícias, as opiniões e as deficiências referentes à corporação são legitimadas. Notou-se, nos trechos analisados, que o usuário produtor de conteúdo corporativo é uma ferramenta da comunicação institucional, que pode construir, (des)construir e, até mesmo, (re)construir a identidade, imagem e reputação organizacional.
\end{abstract}

Palavras-chave: Comunicação institucional. Facebook. Repercussão negativa 


\begin{abstract}
This research sought to understand how Facebook customers and users create contents that take effects on the institutional communication of the organization TIM (Telecom Italia Mobile). From the organizational communication propositions and the methodological procedures of the Content Analysis, of the French researcher Laurence Bardin, the investigation was developed. This coursework's focus is Facebook's communication, produced by information and opinions shared, commented and liked by the users. With the analytical process, it was observed that when negative content exposition on the worldwide web become news, the opinion and deficiencies related to the corporation are legitimized. It was noticed, on the sections analysed, that the enterprise content producer user is a tool of institutional communication, that can construct, (de)construct and, even, (re)construct the identity, organizational image and reputation.
\end{abstract}

Keywords: Institutional communication. Facebook. Negative reverberation.

\section{Introdução}

O trabalho intitulado A comunicação institucional e o conteúdo gerado pelos usuários no Facebook envolvendo a companhia TIM é o estudo que aborda a análise da comunicação institucional na rede social ${ }^{1}$ Facebook, com base metodológica na Análise de Conteúdo.

A partir dos estudos da comunicação organizacional e as proposições da pesquisadora Margarida Kunsch (2003), pode-se afirmar que a comunicação institucional implica conhecer a organização e compartilhar seus atributos, como missão, visão, valores, filosofia e políticas. Valsani (2006) explica que a comunicação institucional embasa a missão e os valores, a identidade corporativa, a história, as lideranças e os instrumentos de uma organização.

Nesse contexto, o objeto de investigação da pesquisa é a comunicação no Facebook, gerada por usuários e consumidores insatisfeitos com os produtos e serviços da companhia TIM (Telecom Italia Mobile) Participações S.A. O conteúdo analisado foi publicado no período do segundo semestre de 2011.

O problema que se pretendeu responder com a pesquisa é: de que forma os usuários do Facebook geram conteúdo que produz sentidos na comunicação institucional de uma organização? Assim, o material de análise investigado é a rede social Facebook, especificamente as informações organizacionais compartilhadas, curtidas e comentadas por usuários relativos à TIM.

Esse ambiente digital criado em 2004, denominado Facebook, proporciona aos usuários a possibilidade de opinar, criticar e denunciar atitudes e posturas de organizações. De acordo com a pesquisa realizada pelo Ibope Nielsen Online, divulgada pelo UOL Notícias (2011), no mês de setembro o Facebook conquistou 750 milhões de internautas no mundo.

Já os autores Pavão Júnior e Sbarai (2011), norteados pela pesquisa da ComScore, afirmam que em agosto do ano de 2011 foram 28,6 milhões de usuários brasileiros que acessaram o Facebook. Segundo eles, os estudos do Emarketer ${ }^{2}$ divulgam

\footnotetext{
Segundo Teixeira (2011), redes sociais são grupos de pessoas com interesse em comum, que curtem, compartilham e conversam sobre temas, porém não significa necessariamente por meio da internet. Já as mídias sociais, são os meios em que são construídas as redes sociais, compartilhando e disseminando conteúdo. Teixeira (2011) diz que o Facebook pode ser considerado mídia e rede social, pois permite divulgar e compartilhar conteúdo, além de conectar pessoas com interesses em comum. Porém, não há o objetivo de aprofundar esses conceitos, pois fugiria do propósito da pesquisa, que é compreender como os usuários do Facebook geram conteúdo que produz sentidos na comunicação institucional da organização, precisamente da companhia TIM.

Pesquisa e analisa sobre marketing digital, mídia e comércio.
} 
que diariamente os usuários publicam 250 milhões de fotos, comentam ou curtem 2 bilhões de posts ${ }^{3}$ e interagem com 900 milhões de atrações, como páginas individuais, eventos e comunidades.

E a partir desse novo processo de comunicação foi desenvolvida a pesquisa orientada pela fundamentação metodológica da Análise de Conteúdo (AC), da pesquisadora francesa Laurence Bardin. Ela explicita que a AC "oscila entre os dois polos do rigor da objetividade e da fecundidade da subjetividade. Absolve e cauciona o investigador por esta atração pelo escondido, o latente, o não aparente, o potencial de inédito (do não dito), retido por qualquer mensagem" (BARDIN, 2011, p. 15).

Assim, o trabalho justifica-se para a área da comunicação organizacional por ser a Análise de Conteúdo corporativo gerado nas redes sociais que 'arranham' a comunicação institucional da organização. Segundo Kunsch (2003), a comunicação institucional é responsável pela construção da imagem e identidade corporativa forte e positiva de uma organização. Para Rego (2002), a imagem da empresa significa aquilo que a empresa quer projetar; já a identidade é o caráter, o conceito e a personalidade da organização. "A imagem é a extensão (a sombra) dessa identidade" (REGO, 2002, p. 163).

$O$ estudo também contribuiu para o curso de Gestão da Comunicação Organizacional e Negócios, por ser estudado sob a perspectiva dos estudos teóricos da pesquisadora Margarida Kunsch, referência nas teorias da Comunicação Organizacional. A AC, no ambiente online, também trouxe um retorno social, pois se pretendeu compreender o ambiente - Facebook, que possibilita ao usuário interagir e participar, direta ou indiretamente, da comunicação institucional de uma organização.

\section{O conteúdo referente à companhia TIM e os seus efeitos}

O conteúdo gerado pelo usuário estudado a respeito da companhia TIM foi produzido durante o segundo semestre de 2011. Para a análise, foi limitado o conteúdo corporativo publicado nos meses de outubro e novembro. Foram escolhidos esses dois meses, por ter havido mais publicações devido a problemas nos serviços da empresa, que incluem telefonia fixa, móvel e acesso à internet (móvel e fixa).

As reclamações publicadas no Facebook foram referentes à ausência de sinal, falha na rede, celulares com sinal de ocupado, ligações não completadas e não recebidas e atraso no envio e no recebimento de mensagens. E foram por meio de informações e opiniões geradas pelo Facebook que as reclamações se disseminaram.

No Facebook, surgiram imagens e textos reclamando da organização TIM. E a partir dessas publicações, as informações postadas foram compartilhadas, comentadas e curtidas. Segundo Sakate e Sbarai (2012), a cada um minuto, 451 novos usuários são cadastrados no Facebook, 173.000 fotos são publicadas e 1,9 milhão de usuários clicam no 'botão' curtir ou fazem comentários. Nesse contexto, foi compreendido o conteúdo corporativo no Facebook, bem como os seus efeitos.

Kirkpatrick (2011) ressalta que o Facebook facilita a organização das pessoas e oferece aos indivíduos em sociedades de todo o mundo mais poder em relação às instituições. Ele afirma que o efeito Facebook pode ser uma força construtiva ou até mesmo destrutiva, pois pode (des)estabilizar instituições.

Tadeu (2008) explica que a marca leva anos para ser construída, porém a sua destruição pode ocorrer em minutos. Ele diz que, quando exposto na internet, o dano pode ser muito maior e mais rápido e, ainda, pode "manchar ou arrasar a reputação de uma empresa num piscar de olhos". O autor salienta que as redes sociais têm forte influência quanto à sustentação ou destruição da marca ou reputação de uma empresa.

Conforme Kirkpatrick (2011), no Facebook todos podem ser editores, criadores de conteúdo, produtores e distribuidores. "Os clássicos papéis da velha mídia estão sendo desempenhados por todos. O efeito Facebook pode criar uma repentina convergência de interesses em torno de uma notícia, uma música ou um vídeo do Youtube" (KIRKPATRICK, 2011, p. 17).

\footnotetext{
${ }^{3}$ Informações publicadas no ambiente digital, organizadas de forma que as mais atualizadas sejam visualizadas primeiro.
} 


\section{Conteúdo negativo atinge a comunicação institucional}

Segundo Qualman (2011), as mídias sociais permitem que os consumidores se expressem instantaneamente sobre o que gostam ou não, desde produtos e serviços até a atuação do governo. Ele diz que, no passado, milhões de consumidores frustrados não se incomodavam em comentar.

O autor ainda apresenta um estudo ${ }^{4}$ realizado pelo Instituto de Planejamento Estratégico, cujo resultado é que $96 \%$ dos consumidores não satisfeitos reclamavam. Desses, 63\% dos consumidores silenciosamente insatisfeitos com a empresa não consumiam mais produtos dela. $\mathrm{E}$, ainda, dos $4 \%$ de consumidores insatisfeitos que chegaram a reclamar, sete de dez fariam negócio novamente com a empresa se ela lidasse com os problemas de forma correta, e 19 de 20 , se suas reclamações fossem atendidas com rapidez.

Já em 2008, na reportagem da jornalista Viviane Maia, publicada por Pequenas Empresas \& Grandes Negócios, há declarações dos pesquisadores norte-americanos Josh Bernoff e Charlene Li. Para eles, os usuários são pessoas com perfil mais reivindicador, ou seja, são pessoas que não aceitam imposições, buscam seus direitos e não têm medo de brigar.

Nesse sentido, com o desenvolvimento e aperfeiçoamento da internet, das redes sociais, das mídias sociais e do Facebook, a frustração e a decepção dos consumidores são manifestadas de formas diferentes. O usuário produtor de conteúdo possui voz, pode reclamar, pode compartilhar suas reclamações, pode influenciar o comportamento dos consumidores e, consequentemente, afetar a comunicação institucional da corporação.

Segundo Rego (1986), as publicações institucionais projetam a boa imagem da empresa, mostrando sua organização, seus produtos, sua qualidade e suas técnicas. Entretanto, quando há publicações institucionais com conteúdos negativos, há o sentido inverso, isto é, a projeção da má imagem da organização, ilustrando as suas deficiências. E quando analisada no ambiente digital, essa projeção é imediata.

Para Qualman (2011), os consumidores buscam recomendações de colegas nas mídias sociais sobre produtos e serviços. Ele aponta que $78 \%$ das pessoas se baseiam no que os outros dizem, enquanto $14 \%$ se baseiam em propaganda.

De acordo com estudos realizados pela Deloitte $^{5}$, nas mídias sociais a reputação de uma empresa perde o controle de sua liderança, ou seja, a empresa deixa de ter controle sobre o processo de geração e disseminação da informação. Ainda, segundo informações da Deloitte, a reputação corporativa se define pelas ações das pessoas, dos clientes e de outros influenciadores online. A pesquisa da Deloitte salienta que na internet os consumidores podem expressar suas preferências por fornecedores e produtos, o que influencia o comprador na hora da escolha, pois os consumidores chegam a confiar em estranhos virtuais por se identificar com eles.

A partir dessas mudanças, a Deloitte define o novo consumidor social como o indivíduo que considera opiniões online de amigos e estranhos, tende a comprar mais online do que offline, quer prover feedback (retorno) sobre produtos e serviços, espera experiência melhor online do que offline, lê e cria rankings, blogs etc., busca apoio para conectar-se aos seus semelhantes e usa novos canais online e ferramentas de comunicação.

Em entrevista a Pequenas Empresas \& Grandes Negócios, realizada por Maia (2008), o estrategista de mídias sociais, Wagner Fontoura, ressalta que os protagonistas da mídia social são os indivíduos. Para ele, o perfil do consumidor mudou e esse indivíduo controla a interação com as marcas. Segundo ele, para que a empresa tenha credibilidade, as pessoas têm que falar positivamente da empresa

\footnotetext{
${ }_{5}^{4}$ Qualman (2011) ressalta que o estudo foi divulgado pelo The American Salesman Journal, em 2003.

Segundo informações do site www.deloitte.com, Deloitte é a marca sob a qual profissionais em empresas independentes, localizadas em várias partes do mundo, colaboram para oferecer serviços nas áreas de Auditoria, Consultoria Tributária, Consultoria em Gestão de Riscos Empresariais, Corporate Finance, Consultoria Empresarial e Outsourcing. Essas firmas são membros da Deloitte Touche Tohmatsu Limited (DTTL), uma empresa privada do Reino Unido, limitada por garantia.
} 
para os outros de forma espontânea e nunca de maneira imposta.

Sendo assim, quando os consumidores da TIM e (ou) usuários do Facebook produzem conteúdo corporativo negativo, a comunicação institucional da companhia é exposta de forma pública. Nesse caso, são exposições de opiniões negativas na rede mundial, que atingem e afetam a identidade, imagem e reputação da organização. Para Turchi (2010), o risco para com as marcas ocorre porque não há o controle no ambiente digital e, ainda, pouco controle sobre a repercussão de certas ações, expondo as organizações a consequências indesejáveis. "Essa falta de controle se deve ao processo atual de geração de conteúdos, que pode ser feito por qualquer um, bem como sua disseminação na web, que ocorre de forma extremamente veloz, devido ao alto grau de conexão entre as pessoas" (TURCHI, 2010).

\section{Informações e opiniões se tornam pautas jornalísticas}

Por meio do conteúdo corporativo gerado pelos usuários do Facebook, as informações e opiniões negativas sobre a companhia TIM se tornaram pautas $^{6}$ para os jornalistas e, por conseguinte, notícias em jornais digitais.

Monteiro (2003) afirma que o espaço publicitário é pago, o que para o público pode ser interpretado como o ambiente em que a instituição só publica o que lhe convém, já a publicação de notícias e reportagens sobre a organização na imprensa é gratuita, sendo assim, assume o caráter de imparcialidade e, logo, aumenta a credibilidade do que é dito sobre a instituição.

Beltrão (1969, p. 82) define a notícia como a "narração dos últimos fatos ocorridos ou com possibilidade de ocorrer, em qualquer campo de atividade e que, no julgamento do jornalista, interessam ou têm importância para o público a que se dirigem". Melo (1994, p. 49) conceitua a notícia como "o relato integral de um fato que já eclodiu no organismo social".

Já Monteiro (2003, p. 142) entende que a notícia institucional deixa de ser um espelho da realidade, e torna-se o "processo de interação social e de uma série de negociações, o que empresta a ela um papel sociopolítico nas sociedades contemporâneas". A autora compreende que a promoção de acontecimentos e a produção de notícias permitem que as instituições se insiram no espaço público, construindo não apenas a imagem institucional, como também a realidade do campo em que atuam.

Sendo assim, quando as informações e opiniões do usuário produtor de conteúdo corporativo se tornam notícias, a comunicação institucional da TIM se expõe mais uma vez no ambiente digital, entretanto, dessa vez com credibilidade, imparcialidade e veracidade. Nesse sentido, (re)forçam ainda mais as opiniões negativas e deficiências da organização no espaço público, legitimando as informações produzidas no Facebook.

De acordo com o estudo da agência S2 Comunicação, publicado em 2009 no Ideia 2.0, em média, 67\% dos profissionais de mídia usam as redes sociais com objetivos profissionais e pessoais. Os dados ainda revelam que os jornalistas estão usando as redes sociais para trabalhar, fazer pautas, ouvir pessoas e consumidores.

Terra (2009) explica que as mensagens descendentes e unidirecionais cedem espaço ao relacionamento, pois os usuários podem produzir conteúdo e trocar arquivos, expressão e participação, e, ainda, podem concorrer com o papel da imprensa.

Segundo estudo publicado pela Textual, que pesquisou os efeitos das mídias sociais no trabalho jornalístico, $82 \%$ dos jornalistas ouvidos concordam com a influência dos conteúdos das mídias sociais na pauta da mídia brasileira. E somente $18 \%$ não concordam com essa influência. Na mesma pesquisa, foi perguntado sobre a nota que os jornalistas dariam ao conteúdo gerado pelas mídias sociais. De 0 a 5 , a maior porcentagem foi para a nota 3 , com $54 \%$.

\footnotetext{
Conforme informações do Manual da Redação da Folha de S. Paulo (2006, p. 21), pauta é o primeiro roteiro para a produção de textos jornalísticos. Segundo o Manual, a pauta não nasce da imaginação do jornalista, contudo do trabalho com as fontes de informação, da leitura diária de diversas publicações, da observação da vida, da reflexão sobre os acontecimentos, da capacidade de manter o olhar atento e curioso, e da percepção do que seja útil ou válido para a informação e o entendimento do leitor..
} 
Para Monteiro (2003), a notícia institucional assume o caráter político, mas sem deixar as características informativas, passando a ser utilizada de forma estratégica nos segmentos sociais que detêm o poder de decisão ou de influenciar decisões que possam beneficiar a instituição. Porém, a notícia institucional composta por conteúdo negativo referente à organização tende ao malefício, pois atinge a reputação organizacional.

Conforme explicitado acima, o conteúdo corporativo sobre a TIM produzido pelos usuários do Facebook resultou em diversas notícias publicadas no ambiente online. Para a análise foram feitos recortes dos fatos veiculados no jornal digital regional - sediado em Maringá, no noroeste do Paraná - e estadual - em Curitiba. Duas reportagens foram recortadas, sendo a primeira do jornal regional $(\mathrm{O}$ Diário do Norte do Paraná) e a segunda do jornal estadual (Gazeta do Povo).

E a partir das regularidades na postagem, considerando o problema da pesquisa e o período limitado, foram realizados os recortes de imagem e texto. Em seguida, foi construído o corpus $^{7}$ de análise baseado nos princípios e procedimentos da AC e da pesquisa qualitativa. Bardin (2011, p. 37, grifos da autora) define a AC como o "conjunto de técnicas de análise das comunicações". Ela afirma que a análise qualitativa é mais intuitiva, mais maleável e mais adaptável a índices não previstos ou à evolução das hipóteses.

\section{Percurso de análise: (des)construção da imagem e identidade}

Norteado pelas obras centrais da pesquisadora Margarida Kunsch, pelos estudos da comunicação institucional e pelo procedimento da AC, o referencial teórico e metodológico da pesquisa foi desenvolvido.
Sendo assim, considerando os objetivos traçados para esta investigação, foram feitos dois recortes de postagem no Facebook, relativos à companhia TIM, bem como dois recortes de notícias publicadas no ambiente digital.

Para a investigação, foi utilizada a técnica da AC de Bardin (2011), que é dividida em três fases: a pré-análise, a exploração do material e o tratamento dos resultados (inferência e interpretação ${ }^{8}$ ).

A fase da pré-análise foi desenvolvida a partir da leitura flutuante ${ }^{9}$, formulação dos objetivos, constituição do corpus de análise e escolha de unidades de registro e de contexto.

Nesse sentido, o objetivo analítico foi formulado e consiste em identificar os sentidos produzidos e (re)produzidos por usuários do Facebook que atingem a comunicação institucional da TIM. Já a constituição do corpus foi realizada a partir das contribuições de Margarida Kunsch e dos estudos da comunicação institucional.

Nessa primeira fase da análise foi adotado o critério linguístico para a escolha das unidades de registro, sendo por meio de palavras que os usuários publicaram a respeito da companhia. Bardin (2011) explica que todas as palavras do texto podem ser levadas em consideração ou podem-se reter unicamente às palavras-chave ou palavras-tema.

Já na segunda fase da análise, em que ocorre a exploração do material, foi elaborado o processo de categorização. A partir das unidades de registro e de contexto selecionadas, foi encontrada e indicada a frequência com que aparecem as curtidas, os compartilhamentos e os comentários a respeito da TIM. Dessa forma, foi utilizado o critério de categorização denominado léxico. Bardin (2011) explica que o critério léxico é a classificação das palavras, segundo o seu sentido. No caso da investigação, as palavras foram classificadas de acordo com o sentido negativo, ou, ainda, informações e opiniões negativas. Além disso, a autora destaca que a análise qualitativa das

Bardin (2011, p.126, grifos da autora) explica que "corpus é o conjunto dos documentos tidos em conta para serem submetidos aos procedimentos analíticos".

${ }^{8}$ Inferência é a dedução de maneira lógica e interpretação é a significação concedida às características do texto, segundo Bardin (2011).

Para Bardin (2011), a fase que consiste em estabelecer contato com os documentos para a análise e em conhecer o texto permitindo impressões e orientações é denominada leitura flutuante. 
unidades de vocabulário, por ordenação frequencial segundo o sentido, fornece informações.

Assim, por meio da análise lexical, foi explorado o material e realizada a terceira fase da análise. O primeiro recorte da análise é a publicação de um usuário que questiona os problemas de serviço da TIM. A foto publicada contém palavras relacionadas à companhia. Nessa frase, foram classificadas as palavras ${ }^{10}$ : "reféns", "ligações derrubadas e picotadas", "picota a voz a cada 3 segundos", "caos" e "exigir nossos direitos".

Nesse recorte, nota-se que os consumidores e usuários produtores de conteúdo estão indignados e descontentes com os serviços da TIM. Quando publicada a palavra "reféns", pensa-se em bandidos, sequestradores e crimes. Mas, refém? Cativos? Em troco de quê? São consumidores que a organização mantém em seu poder para garantir lucros por meio de produtos e serviços vendidos? São esses os sentidos que direcionam os consumidores e se significam no ambiente digital. São sentidos agregados à comunicação institucional da corporação. São consumidores intimidados com ligações cortadas em segundos que se apropriam da palavra "reféns".

E, ainda, quando postada a palavra "caos" a proporção dos "reféns" é aumentada e sugere desespero para os consumidores, pois aponta que o problema da organização não é local, porém regional, e até mesmo nacional. E quando surgem as palavras "exigir nossos direitos", surge, também, o consumidor que aproveita os recursos do Facebook e que conhece os efeitos dessa mídia social para reivindicar o que ele comprou e o que foi prometido pela organização.

Nessa postagem, 150 pessoas curtiram e 1.782 compartilharam. A partir desses indicadores quantitativos, percebe-se a medida de intensidade de influencia, tanto para os consumidores, como para os possíveis futuros consumidores.

Em seguida, foram analisados os comentários relativos à foto publicada. As palavras classificadas foram: "mudei de operadora", "propaganda são enganações", "problemas com a tim", "realmente está péssima mesmo", "Ninguém merece essa TIM", "eles vendem planos que depois não podem sustentar", "passo ate dia sem sinal", "uma vergonha pois pagamos caro o serviço q nao é prestado" e "UMA VERGONHA".

Nas palavras classificadas já se percebe a repercussão do conteúdo corporativo gerado pelos usuários insatisfeitos. São expressões que (re)forçam a intensidade e consistência das publicações.

Almeida (2009) afirma que a identidade organizacional se revela nas histórias e nos comportamentos do cotidiano, e ainda requer perspectivas da organização como um todo. Ela ressalta que é a partir da percepção e da interpretação da identidade pelos variados públicos que a imagem corporativa é constituída. Segundo ela, nas interpretações e na consolidação das identidades e imagens é que se constitui a reputação.

Sendo assim, por meio de expressões percebidas e interpretadas pelo público do Facebook que a imagem e a identidade da TIM foram (des) construídas e a sua reputação atingida. São comportamentos do cotidiano, construídos por usuários, que tornam fraca e subtraem valores da comunicação institucional organizacional.

No segundo recorte analisado, publicado em 5 de outubro de 2011, o consumidor postou uma foto que consiste em reclamações, por meio do trocadilho do slogan e da logomarca da TIM. $\mathrm{Na}$ foto, foram selecionadas as seguintes palavras da logomarca: "TINHA SINAL", e do slogan: "Você, sem comunicação".

O slogan oficial da TIM é "Você, sem Fronteiras", entretanto o usuário produtor de conteúdo (re)produziu a frase para "Você, sem comunicação". Assim, observa-se que o indivíduo, com a sua voz nas mídias sociais, interferiu na identidade e imagem visual da organização, já que o slogan aparece abaixo da logomarca. E ainda, em vez da palavra TIM se situar dentro do formato do símbolo, há as palavras "TINHA SINAL". Se a intenção da companhia é valorizar a tecnologia e a inovação com a logomarca, isto é, com a cor, linhas, traços ou forma, com o trocadilho ocorre o inverso. Para a empresa do setor de telecomunicação ser vista ausente

${ }^{10}$ As palavras classificadas são transcritas e reproduzidas por escrito de acordo com as publicações, respeitando as letras maiúsculas/
minúsculas e destacando que não foram feitas alterações para a gramática normativa a fim de ser fiel às postagens no Facebook. 
de comunicação é inaceitável. Sendo assim, com o trocadilho, percebe-se que o indivíduo interferiu na estratégia corporativa da TIM e, ainda, afetou a identidade da organização.

Nessa foto houve 11 pessoas que curtiram e 4.833 compartilhamentos. Nessa proporção de intensidade, percebe-se que o usuário produtor de conteúdo corporativo se significa e os usuários que curtem e compartilham também produzem sentidos, comprometendo a comunicação institucional da TIM.

Já nos comentários da foto, foram classificadas as determinadas palavras: "não aguenta mais ligar para alguem e o celular fora de área", "ligação cortando", "ligação caindo do nada", "mensagem que é enviada e so chega 5h depois", "Quem não tiver agüentando mais, curti ae !", "que tal a gente migrar" e "passou a tarde inteira fora do ar!".

Pensando em uma empresa que vende qualidade de sinal, praticidade, cobertura e capacidade de rede e chamadas de longa distância, e analisando as palavras classificadas acima, há uma forte discordância. É o conjunto de palavras que aponta para opiniões de insatisfação e revolta dos consumidores. São expressões que indicam uma contradição em relação aos serviços da TIM e, ainda, que sugerem a troca de companhia, (re)vertendo em prejuízos financeiros para a empresa.

Em continuação da análise, precisamente dos desdobramentos e das repercussão das informações e opiniões geradas por usuários no Facebook, foram escolhidas duas notícias de jornais. A primeira é do jornal online regional, publicada em 5 de novembro de 2011, às 2h. Essa notícia possui o título: "Pane na TIM provoca revolta em usuários".

As palavras classificadas foram: "revoltados", "série de problemas", "ligações não completadas, não recebidas, celulares com sinal de ocupado o tempo todo, falta de torre, falha na rede e mensagens de texto que só chegam ao destinatário um dia depois de enviadas", "uma das prejudicadas pela falha de serviço", "não conseguiu fazer ligações importantes para alguns clientes", "não consegui receber ligações deles" "ficou na mão", "não conseguia telefonar para um deles" "recorreu a um celular de outra operadora", "gastou muito tempo para encontrá-los", "Foi um transtorno muito irritante", "enfrentou apagões no sistema três vezes", "a ligação não se completava" e "reclamou que estava sem sinal".
Por meio desse recorte, observa-se a frequência forte das palavras: "não", "falta" e "falha". São expressões que indicam e (re)forçam os fatos negativos, e consequentemente a notícia negativa, causando impactos significativos na comunicação institucional da corporação. E, ainda, quando noticiada em um jornal online, a informação se torna pública e não mais restrita somente aos usuários do Facebook, expandindo-a em uma velocidade veloz.

Além da notícia online, no final do texto há mais uma forma de disseminar a informação. Há um ícone com o 'botão' do Facebook, que permite compartilhar a notícia do jornal na mídia social. Assim, mais uma vez a informação gerada no Facebook, que foi disseminada no site do jornal, volta para o Facebook, contudo mais intensa, pois foi legitimada pelo jornalismo. Lopes (2000) salienta que a mídia está sempre ao lado do consumidor.

A segunda notícia analisada é de um jornal online estadual, publicada no dia 3 de novembro de 2011, às 21h 31. A notícia é titulada de "Usuários da TIM reclamam de falha na rede" e, ainda, possui a seguinte linha fina "Consumidores usaram as redes sociais para reclamar da falta de sinal em celulares e internet 3G".

Para a análise, foram classificas as palavras: "reclamaram de falha no sinal de celular e internet 3G", "reclamar do serviço", "falha nacional na rede", "mas não obteve sucesso", "ligações entre números da operadora não eram completadas e recebiam a mensagem de rede ocupada" e "tiveram problemas com a operadora desde as 18 horas".

Mais uma vez o substantivo "falha" e o verbo "reclamar" são observados de forma constante, indicando os atributos negativos e as deficiências nos serviços da TIM. Segundo Bueno (2009), a imagem da organização é construída ao longo do tempo, por suas ações cidadãs, pela excelência dos produtos e serviços, pelo respeito aos consumidores, pela inovação dos produtos e por sua postura ética e transparente. Entretanto, quando há carências nos produtos e serviços da organização, repercute na construção da imagem e, até mesmo, na identidade da corporação. E, ainda, essa notícia analisada possui no site do jornal 47 comentários. O que contribui com mais opiniões a respeito da companhia.

Lopes (2000, p. 20) destaca que "as boas notícias tendem a ocupar menos espaço nas manchetes do que as desfavoráveis. A empresa que não 
trabalha de forma pró-ativa corre o risco de ser lembrada apenas quando algo negativo acontece". A autora afirma que a formação ou manutenção da boa imagem, depende da forma em que é projetada diante dos olhos dos formadores de opinião e, ainda, tanto a imagem positiva como a negativa dependem da forma de interação com a mídia.

Dessa forma, por meio do procedimento analítico constata-se que as notícias negativas referentes à TIM se projetam por mais tempo e mais intensidade na mente do consumidor, 'arranhando' a identidade e imagem corporativa, permitindo a perda de credibilidade da empresa e gerando percepções negativas.

\section{Considerações finais}

Cada vez mais os consumidores se voltam para as mídias sociais e contribuem, positiva ou negativamente, com a comunicação institucional da organização. Essas mídias sociais, como o Facebook, se tornam porta-vozes da sociedade e podem atingir as corporações, por meio de informações e opiniões geradas por usuários no ambiente digital. E as pessoas, sabendo da força e dos efeitos do Facebook, utilizam desse recurso e ferem relações duradouras entre organizações e os seus públicos.

Já em 2008, em entrevista feita por Maia, publicada pela Revista Época Negócios, a pesquisadora norte-americana em mídia social, Danah Boyd, explica que se a marca não é falada, ela não existe, ou seja, por isso é importante falar bem ou mal da empresa, desde que falem da marca. A pesquisadora diz que as empresas precisam aprender a lidar com os comentários negativos e criar diálogos com os internautas. Tadeu (2008) ainda afirma que os especialistas são unânimes em destacar que quando uma pessoa ou grupo está disposto a protestar, a pior atitude da empresa é ignorar. "Mesmo que os ataques sejam pequenos, as empresas não podem se dar ao luxo de cruzar os braços" (TADEU, 2008).

Nesse sentido, é fundamental as organizações investirem, administrarem e desenvolverem estratégias para os momentos corporativos turbulentos - embora sempre norteadas pela transparência, franqueza e ética. Dessa forma, uma das estratégias é gerenciar relacionamentos, por meio dos profissionais de comunicação, partindo da comunicação integrada. Na situação da TIM, poderia ser desenvolvida a estratégia que possibilitasse profissionais online nas mídias sociais, que respondessem aos usuários e consumidores, admitindo as deficiências na organização, mas apresentando ações eficientes, objetivas e imediatas para as soluções.

Sendo assim, a partir do procedimento analítico desenvolvido, percebe-se que o usuário produtor de conteúdo corporativo se significa no Facebook, e até mesmo, (des)constrói a imagem e a identidade da organização. Porém, esse usuário também pode contribuir com o fortalecimento da comunicação institucional. As ações sociais, ambientais e econômicas realizadas por empresas e disseminadas na internet, mídias sociais e no Facebook, são informações que geram opiniões e percepções, e podem se transformar em pautas e notícias positivas. São estratégias planejadas que constroem e (re)constroem a comunicação institucional de organizações, por meio da ferramenta estratégica denominada usuário produtor de conteúdo corporativo.

\section{Referências}

ALMEIDA, A. L. C. Identidade, imagem e reputação organizacional: conceitos e dimensões da práxis. In: $\mathrm{KUNSCH}$, M. M. K. (Org.). Comunicação organizacional: linguagens gestão e perspectivas, São Paulo: Saraiva, 2009. v. 2: A mídia social como fonte de imprensa. Disponível em: $<$ http://www.textual.com.br/_arquivos/textual_pesquisa_midias_sociais.pdf $>$. Acesso em: 12 jun. 2012.

BARDIN, L. Análise de conteúdo. São Paulo: Edições 70, 2011.

BELTRÃO, L. A imprensa informativa: técnica da notícia e da reportagem no jornal diário. São Paulo: Folco Massuci, 1969.

BUENO, W. C. Comunicação empresarial: políticas e estratégias. São Paulo: Saraiva, 2009.

DELOITTE. Disponível em: <www.deloitte.com>. Acesso em: 9 jun. 2012.

DELOITTE. Mídias sociais nas empresas: o relacionamento online com o mercado.2010.Disponívelem: $<$ http:// www.deloitte.com/assets/Dcom-Brazil/Local\%20Assets/ Documents/Estudos\%20e\%20pesquisas/MidiasSociais_ relatorio_portugues.pdf>. Acesso: 9 jun. 2012. 
GAZETA DO POVO. Disponível em: <http://www. gazetadopovo.com.br/economia/conteudo.phtml?tl=1\& $\mathrm{id}=1188328 \&$ tit $=$ Usuarios-da-TIM-reclamam-de-falha-na-rede>. Acesso em: 16 dez. 2011.

IDEIA 2.0. Disponível em: < http:/ /idgnow.uol.com.br/ internet/ideia20/archive/2009/11/04/pesquisa-alertaempresas-para-uso-de-rede-social-pela-mdia/>. Acesso em: 20 jan. 2012.

KIRKPATRICK, D. O efeito facebook: os bastidores da empresa que está conectando o mundo. Rio de Janeiro: Intrínseca, 2011.

KUNSCH, M.M. K. Planejamento de relações públicas na comunicação integrada. São Paulo: Summus, 2003.

LOPES, M. Quem tem medo de ser notícia?: da informação à notícia - a mídia formando ou "deformando" uma imagem. São Paulo: Makron Books, 2000.

MAIA, V. Estão falando bem (e mal) de você. Junte-se a eles. Revista Pequenas Empresas \& Grandes Negócios, v.238. nov. 2008. Disponível em: <http:// empresas.globo.com/Empresasenegocios/0,19125, ERA1691395-2574,00.html>. Acesso em: 9 jun. 2012.

MAIA, V. Falem bem ou mal, mas... Revista Época Negócios, v.21, nov.2008. Disponível em: < http:/ / epocanegocios.globo.com/Revista/Epocanegocios/0,EDG848958377-21,00-FALEM+BEM+OU+MAL+MAS.html>. Acesso em: 9 jun. 2012.
MANUAL de redação: Folha de São Paulo, São Paulo, 2006.

MELO, J. M. A opinião no jornalismo brasileiro. 2.ed. Petrópolis: Vozes, 1994.

MONTEIRO, M. G. M. F. A notícia institucional. In: DUARTE, J. (org.). Assessoria de imprensa e relacionamento com a mídia: teoria e técnica. São Paulo: Atlas, 2003. p.140-160.

ODIÁRIO do Norte do Paraná. Disponível em: < http:/ / www.odiario.com/parana/noticia/508147/pane-na-tim-provoca-revolta-em-usuarios/>. Acesso em: 20 jan. 2012.

PAVÃO JÚNIOR, J.; SBARAI, R. O que quer o senhor das redes. Veja, ed. 2237, n. 40. p. 90-97, set. 2011.

QUALMAN, E. Socialnomics: como as mídias sociais estão transformando a forma como vivemos e fazemos negócios. São Paulo: Saraiva, 2011.

REGO, F. G. T. Comunicação empresarial, comunicação institucional: conceitos, estratégias, sistemas, estrutura, planejamento e técnicas. São Paulo: Summus, 1986.

REGO, F. G. T. Cultura, poder, comunicação e imagem: fundamentos da nova empresa. São Paulo: Pioneira Thomson Learning, 2002. (Coleção Novos Umbrais). 
SAKATE, M.; SBARAI, R. O facebook engole o mundo. Veja, ed. 2255, n. 6, p. 76-87, fev. 2012.

TADEU, E. Reputação é tudo. Revista TI Inside, v. 8, ed. 37, jul. 2008. Disponível em: < http://www.tiinside. com.br/revista.aspx?ID=92215>. Acesso em: 9 jun. 2012.

TEIXEIRA, R. F. Você sabe a diferença entre mídia e rede social? Revista Pequenas Empresas \& Grandes Negócios, jul. 2011. Disponível em: < http://colunas. revistapegn.globo.com/sonasocial/2011/07/01/vocesabe-a-diferenca-entre-midia-e-rede-social/ $>$. Acesso em: 14 jun. 2012.

TERRA, C. F. A comunicação bidirecional, direta e instantânea como o padrão dos relacionamentos organizacionais com seus públicos. Revista Eletrônica Prodam Tecnologia: Empresa de Tecnologia da Informação e Comunicação do Município de São Paulo, São Paulo, v. 2, n. 2. abr./maio/jun. 2009. Disponível em: < http:/ / www.prodam.sp.gov.br/revista/default.asp?nome=edicoes $/ 2 \mathrm{ed}$ artigos.htm>. Acesso em: 9 jun. 2012.

TURCHI, S. O consumidor nas redes sociais. 21 jun. 2010. Disponível em: <http://www.sandraturchi.com. br/e-commerce/06/o-consumidor-nas-redes-sociais $/>$. Acesso em: 18 jun. 2012.
UOL Notícias. Disponível em: <http://tecnologia.uol. com.br/ultimas-noticias/redacao/2011/09/10/facebook-passa-orkut-em-numero-de-usuarios-no-brasil-em-agosto-confirma-ibope.jhtm>. Acesso em: 16 dez. 2011.

VALSANI, F. Comunicação institucional. In: MARCHIORI, M. (Org.). Faces da cultura e da comunicação organizacional. São Caetano do Sul/ SP: Difusão, 2006.
Recebido: 30/08/2012

Received: 08/30/2012

Aprovado: 07/11/2012

Approved: 11/07/2012 